Research Article

Human and Medical Genetics

\title{
$A P O E$ and KLF14 genetic variants are sex-specific for low high-density lipoprotein cholesterol identified by a genome-wide association study
}

\author{
Ying-Hui Lee ${ }^{1 *}$, Ya-Sian Chang ${ }^{2 *}$, Chih-Chang Hsieh ${ }^{3}$, Rong-Tsorng Wang ${ }^{4}$, Jan-Gowth Chang ${ }^{2}$, \\ Chung-Jen Chen ${ }^{5}$ and Shun-Jen Chang ${ }^{6}$ (i) \\ ${ }^{1}$ Kaohsiung Veterans General Hospital, Department of Pathology and Laboratory Medicine, Division \\ of Microbiology, Kaohsiung, Taiwan. \\ ${ }^{2}$ China Medical University Hospital, Center for Precision Medicine, Taichung, Taiwan. \\ ${ }^{3}$ Kaohsiung Medical University, Office of Library and Information Services, Kaohsiung, Taiwan. \\ ${ }^{4}$ Tunghai University, Department of Statistics, Taichung, Taiwan. \\ ${ }^{5}$ Kaohsiung Medical University Hospital, Department of Internal Medicine, Division of Rheumatology, \\ Kaohsiung, Taiwan. \\ ${ }^{6}$ National University of Kaohsiung, Department of Kinesiology, Health and Leisure Studies, Kaohsiung, \\ Taiwan.
}

\begin{abstract}
To demonstrate the loci that relate to high-density lipoprotein cholesterol (HDL-C) levels and genetic sex heterogeneity, we enrolled 41,526 participants aged between 30 and 70 years old from the Taiwan Biobank in a genome-wide association study. We applied the Manhattan plot to display the $p$-values estimated for the relationships between loci and low HDL-C. A total of 160 variants were significantly associated with low HDL-C. The genotype TT of rs 1364422 located in the KLF14 gene has $1.30(95 \% \mathrm{Cl}=1.20-1.42)$ times the risk for low-HDL compared to genotype CC in females $(\log (-p)=8.98)$. Moreover, the genes APOC1, APOE, PVRL2, and TOMM40 were associated significantly with low-HDL-C in males only. Excluding the variants with high linkage disequilibrium, we revealed the rs429358 located in $A P O E$ as the major genetic variant for lowering $\mathrm{HDL}-\mathrm{C}$, in which genotype $\mathrm{CT}$ has $1.24(95 \% \mathrm{Cl}=1.16-$ 1.32) times the risk. In addition, we also examine 12 genes related to HDL-C in both sexes, including $L P L, A B C A 1$, APOA5, BUD13, ZPR1, ALDH1A2, LIPC, CETP, HERPUD1, LIPG, ANGPTL8, and DOCK6. In conclusion, Iow-HDL-C is a genetic and sex-specific phenotype, and we discovered that the APOE and KLF14 are specific to low-HDL-C for men and women, respectively.
\end{abstract}

Keywords: Genome-wide association study, High-density lipoprotein cholesterol, sex-specific, KLF14, APOE.

Received: September 09, 2021; Accepted: December 28, 2021.

\section{Introduction}

The level of low high-density lipoproteins cholesterol (HDL-C) is a common indicator of metabolic syndrome and dyslipidemia (Lazo-Porras et al., 2016). Low HDL-C is also a typical component of familial combined hyperlipidemia (FCHL) (de Graaf and Stalenhoef, 1998; Soro et al., 2003) in which the risk for premature coronary artery disease (CAD) is 2 - to 10 -fold greater than in the general population (Goldstein et al., 1973; Genest et al., 1992; Hopkins et al., 2003). HDL-C also showed a strong inherited basis with heritability estimates of 40-60\% (Weissglas-Volkov and Pajukanta, 2010). Inversely, the higher HDL-C levels showed a protective effect from CAD even after adjustment of non-HDL-C and triglycerides (Emerging Risk Factors Collaboration et al., 2009). Given the public health relevance and the strong genetic component (von Eckardstein et al., 2000; Weiss et al., 2006; Emerging Risk Factors Collaboration et al., 2009; Laks et al., 2011),

Send correspondence to Shun-Jen Chang. National University of Kaohsiung, Department of Kinesiology, Health and Leisure Studies, No. 700, Nanzih District, 81148, Kaohsiung, Taiwan. Email: changsj1104@gmail.com.

*These authors contributed equally to the article. considerable efforts have been made to elucidate the genetic architecture for lower HDL-C levels. In the past, several largescale studies, culminating in the 2013 Global Lipids Genetics Consortium, have contributed to the discovery and validation of genetic loci associated with HDL-C levels (Teslovich et al., 2010; Willer et al., 2013). Interestingly, the disconcordant heritability obtained from different populations and distinct sexes from previous HDL studies (Weiss et al., 2006; Souren et al., 2007) indicated that genetic factors of HDL-C may act in a population- and/or sex-specific manner.

Previously, most genome-wide association studies (GWAS) were carried out in Caucasian populations. Correspondingly, there was a dearth of genetic studies investigating HDL-C in non-European populations, especially in different sexes. While most associated loci relate to the genetic architecture of HDL-C levels in populations worldwide, the degree and specific types of this association are not always consistent. For example, heterogeneity of lower HDL-C effects between males and females suggested that HDL-C levels might be regulated differentially across sexes (Teslovich et al., 2010). A close evaluation of these details is crucial in setting the right public health policies so that the economic and health burden can be reduced. This was evidenced by increases in 
the trait variance after adding population-specific signals (Wu et al., 2013). Therefore, ethnicity- and sex-specific study may be necessary for understanding population-specific HDL-C genetic architecture and resource planning.

This study presents genetic findings in a Taiwanese cohort of both sexes from the Taiwan Biobank (TWB). Identifying genetic loci related to variation in the phenotype may help us to understand how lipid metabolism functions and how effective strategies can be developed to prevent and treat lower HDL-C according to different sexes.

\section{Subjects and Methods}

\section{Study population}

We aimed to explore the genetic variants associated with HDL-C dysfunction and enrolled 41,526 participants aged between 30 and 70 years old from TWB, and we matched them by sex and age. TWB, a nationwide database for research, combines genomic profiles with lifestyle patterns from people in Taiwan to explore the relationships among genetics, the environment, and the etiology/progression of diseases. Each participant underwent biochemical testing (with blood samples) and a physical examination. Blood HDL-C levels were measured after more than 8 hours of fasting. HDL-C levels of the study population were grouped as a new dichotomy variable low-HDL-C for men who have $\mathrm{HDL}-\mathrm{C}<=40 \mathrm{mg} / \mathrm{dl}$, or women who have HDL-C $<=50 \mathrm{mg} / \mathrm{dl}$; others were defined as normal HDL-C. The current uses of tobacco smoking and alcohol consumption were applied for the confounding analysis of genetic variants relating to low-HDL-C. The ethics committee of the China Medical University Hospital Institutional Review Board in Taiwan (CMUH108-REC1-091) has approved this project. Both the Declaration of Helsinki and the Good Clinical Practice Guidelines were followed and informed consent granted by all participants. Both the Declaration of Helsinki and the Good Clinical Practice Guidelines have observed, and informed consent have been granted by all participants.

\section{Genotyping and quality control}

All samples were genotyped using Affymetrix Axiom genotyping array (chip: TWB2), including 680K SNPs. Quality control (QC) was applied to leave out those SNPs with low call rate $(<95 \%)$, minor allele frequencies (MAF) less than 0.05 , and deviations from the Hardy-Weinberg equilibrium ( $\mathrm{p}<0.05$; library HardyWeinberg of R program).

\section{Statistical analysis}

We used a total of 266,556 SNPs that passed the quality control for GWAS. The clinical characteristics between subjects with and without low-HDL-C were compared, applying a chi-square test for categorical variables and a t-test for continuous variables. The $p$-values estimated by the chi-square test (chisq.test function of $\mathrm{R}$ program) for the association between genetic variants located on each chromosome pair (22 autosomes and X, Y sex chromosomes) and low- HDL-C were presented in Manhattan plots (library qqman), using the R-program provided by Turner (Turner, 2014). We applied a chi-square test for trend to assess the dose-response effect of various number of alternative allele (or genotypes) on the low-HDL-C rate. We conducted a logistic regression model for estimating the odds ratios (ORs) as well as $95 \%$ confidence intervals $(95 \% \mathrm{CI})$ that followed Poisson distribution for the associations between genetic variants and low-HDL-C after adjustment of variables including total cholesterol, triglycerides, and body mass index (BMI) (library aod of R program). Moreover, an analysis of variance (ANOVA) was used to detect the mean differences of HDL-C level among genotypes. The Locuszoom plot was employed to visualize the regional strength and associations between loci and low-HDL-C related to local linkage-disequilibrium (LD), recombination patterns, and genomic position (locuszoom v1.4 for python v2.7) (Pruim et al., 2010). For the GWAS, after application of the Bonferroni correction for multiple testing, the significance was determined at $p<1 \times 10^{-8}$. For variables such as BMI, total cholesterol, and triglycerides, the significance was determined at $p<0.05$. We used PLINK (v1.9), PERL (v5.16) and R (v3.6) programs to mine raw data, estimate $p$-values and draw plots in CentOS platform (v7.0).

\section{Results}

A total of 20,763 male participants and the same number of female participants from TWB were included in the study. Each male was matched by one female with the same age to ensure the mean age did not significantly differ between genders (mean age $=50.71$ years old, $\mathrm{SD}=11.32$, $p=1.000)$. Considering the associations between demographic characteristics and low-HDL-C, the results showed that diastolic blood pressure, triglycerides, systolic blood pressure, waist circumference, BMI, and fasting glucose were significantly associated with low HDL-C in both males and females (all $p$-values $<0.001$; Table 1 ).

The Manhattan plot showed all $p$-values of loci related to low-HDL-C across 23 pairs of chromosomes and showed a total of 160 variants significantly associated with low HDL-C located on chromosomes 7, 8, 9, 11, 15, 16, 18 and 19 (Figure 1). In addition, all the variants significantly related to low-HDL-C were grouped by sex into their belonging gene (or near gene), the detailed information is listed in Table S1 for males and Table S2 for females. Notably, more variants in chromosome 19 of males showed significant association with low-HDL-C, in comparison to the total number of loci in females (Figure 1A). Chromosome 7 revealed that the female-specific variant, rs1364422, located in the KLF14 gene, was significantly associated with low-HDL-C (Figure 1B). The variants in genes $A P O C 1, A P O E, P V R L 2$, and TOMM40 were significant only in males; moreover, the variants in genes $L P L, A B C A 1$, APOA 5, BUD13, ZPR1, ALDH1A2, LIPC, CETP, HERPUD1, $L I P G, A N G P T L 8$, and DOCK6 have shown significant results in both genders (Figure 2).

Concerning the LD between loci that significantly related to low-HDL-C located in chromosome 19 in males, the Locuszoom plot highlighted recombination rates that existed within these loci $\left(\mathrm{r}^{2}>0.5\right)$. The loci consist of rs 429358 (APOE), rs34342646 (PVRL2), rs6857 (PVRL2), rs34404554 (TOMM40), rs71352238 (TOMM40), rs769449 (APOE), and rs4420638 (APOC1) (Figure 3). The high LD degree of these significant variants suggests that the rs429358 in the $A P O E$ 
Table 1 - Relationship between low-HDL-C and basic demographic and biochemical markers.

\begin{tabular}{|c|c|c|c|c|c|c|}
\hline & \multicolumn{3}{|c|}{ Males $(n=20,763)$} & \multicolumn{3}{|c|}{ Females $(n=20,763)$} \\
\hline & HDL-C Lower & HDL-C normal & $p$-values & HDL-C Lower & HDL-C normal & $p$-values \\
\hline Age (mean \pm SD)) & $50.7 \pm 11.1$ & $50.8 \pm 11.3$ & 0.804 & $51.2 \pm 11.2$ & $50.6 \pm 11.3$ & 0.0001 \\
\hline BMI (mean \pm SD) & $26.8 \pm 3.6$ & $24.8 \pm 3.3$ & $<0.001$ & $25.2 \pm 3.9$ & $22.9 \pm 3.4$ & $<0.001$ \\
\hline $\mathrm{WC}($ mean $\pm \mathrm{SD})$ & $91.9 \pm 9.3$ & $86.7 \pm 9.0$ & $<0.001$ & $84.9 \pm 9.7$ & $79.1 \pm 9.2$ & $<0.001$ \\
\hline $\mathrm{SBP}($ mean $\pm \mathrm{SD})$ & $128.9 \pm 17.3$ & $126.9 \pm 17.5$ & $<0.001$ & $121.2 \pm 18.9$ & $116.7 \pm 18.7$ & $<0.001$ \\
\hline $\mathrm{DBP}($ mean $\pm \mathrm{SD})$ & $80.1 \pm 11.1$ & $78.5 \pm 10.9$ & $<0.001$ & $73.0 \pm 10.5$ & $70.5 \pm 10.5$ & $<0.001$ \\
\hline $\begin{array}{l}\text { Fasting glucose } \\
(\text { mean } \pm \text { SD) }\end{array}$ & $103.3 \pm 29.2$ & $98.2 \pm 21.5$ & $<0.001$ & $98.4 \pm 25.0$ & $92.3 \pm 15.7$ & $<0.001$ \\
\hline $\begin{array}{l}\text { Triglycerides } \\
(\text { mean } \pm \text { SD) }\end{array}$ & $207.0 \pm 195.5$ & $115.6 \pm 77.4$ & $<0.001$ & $145.7 \pm 96.6$ & $84.1 \pm 43.5$ & $<0.001$ \\
\hline
\end{tabular}

HDL-C: high-density lipoprotein cholesterol; BMI: body mass index; WC: waist circumference; SBP: systolic blood pressure; DBP: diastolic blood pressure

(A)

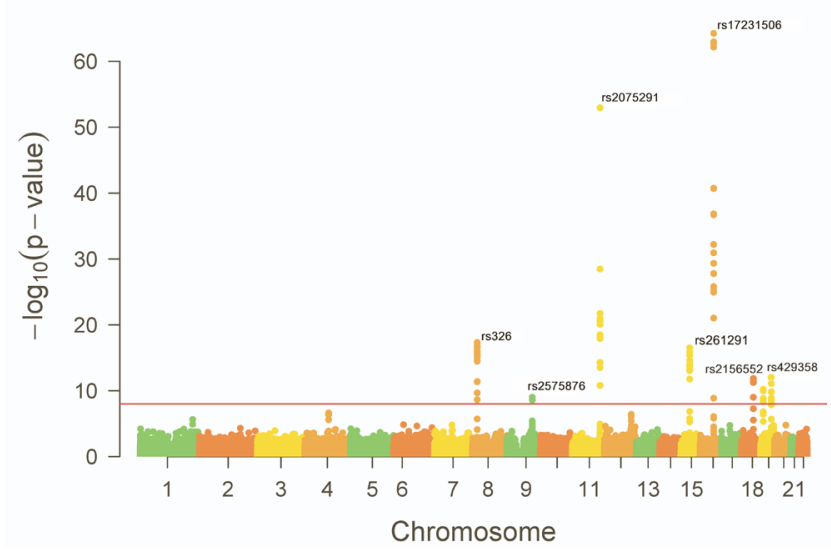

(B)

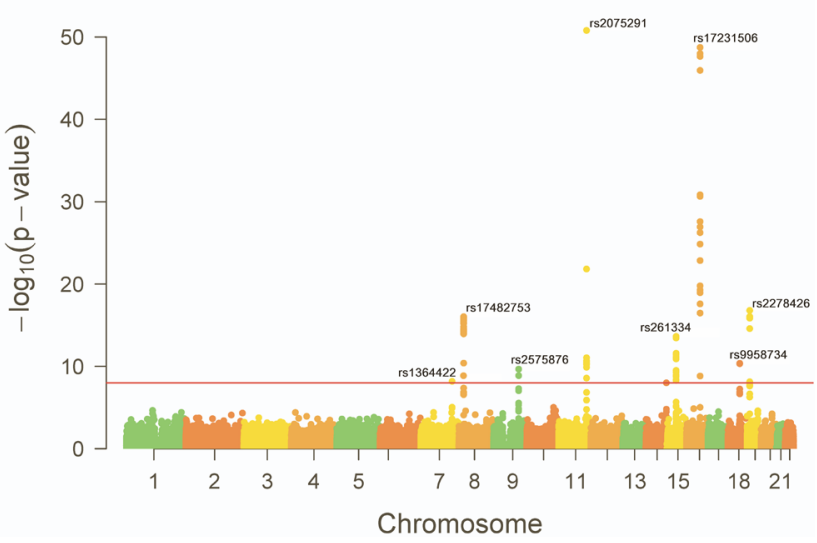

Figure 1 - The Manhattan plots showing the calculated $p$-values for SNPs in all 23 chromosome pairs for the associations with low high-density lipoprotein cholesterol in men (A) and in women (B). The horizontal line indicates the cut-off value for $p$-values $(1 \times 10$-8). The $p$-values were estimated by chi-square test.

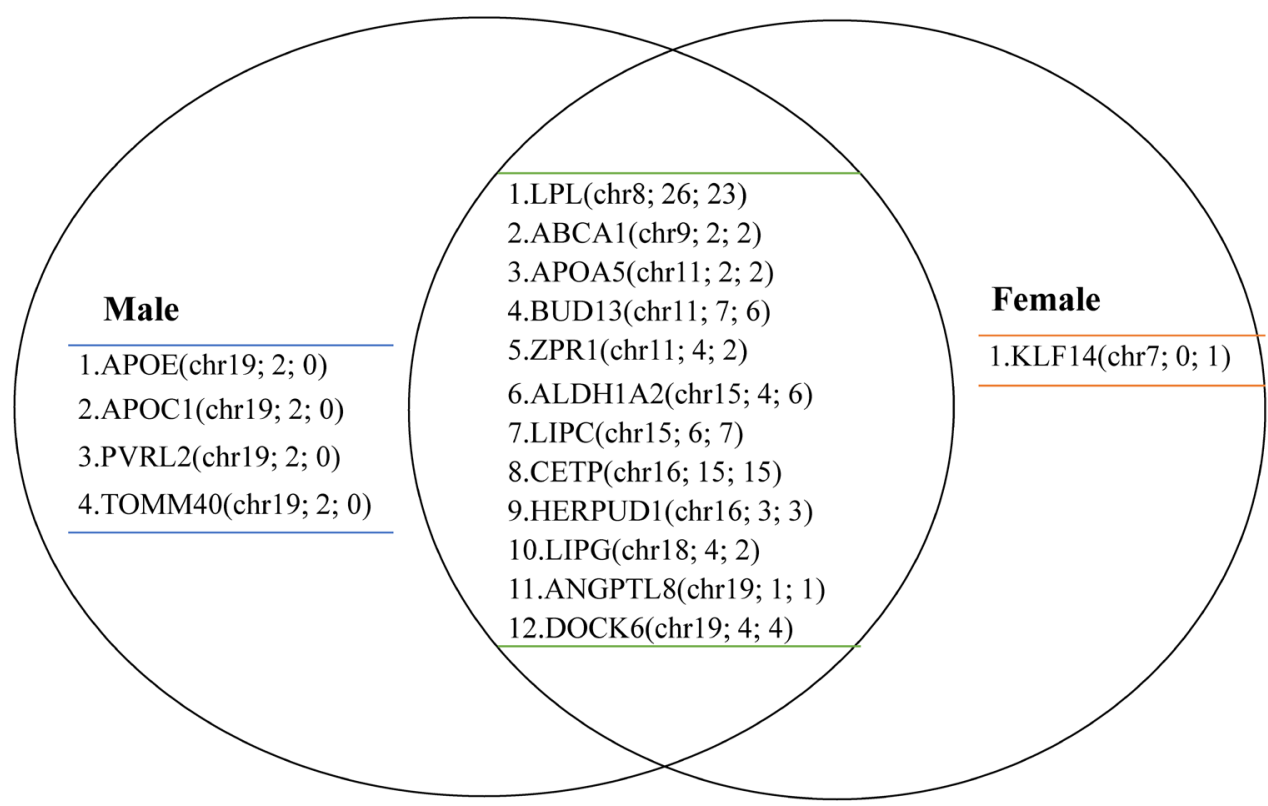

Figure 2 - Summary chart of all the loci is significantly related to low high-density lipoprotein cholesterol (HDL-C). And the gene name of the significant variants located was noted. The chromosome number and number of loci significantly related to HDL-C in men and women were included in the parenthesis. The left part indicates those genes related significantly to low-HDL-C were found only in men, such as $A P O E, A P O C 1, P V R L 2$, and TOMM40. The right part indicates that the polymorphism rs1364422 in gene KLF14 was significantly related to women, but the same effect was not found in men. The middle part indicates the genes were related to low-HDL-C found in both sexes. 


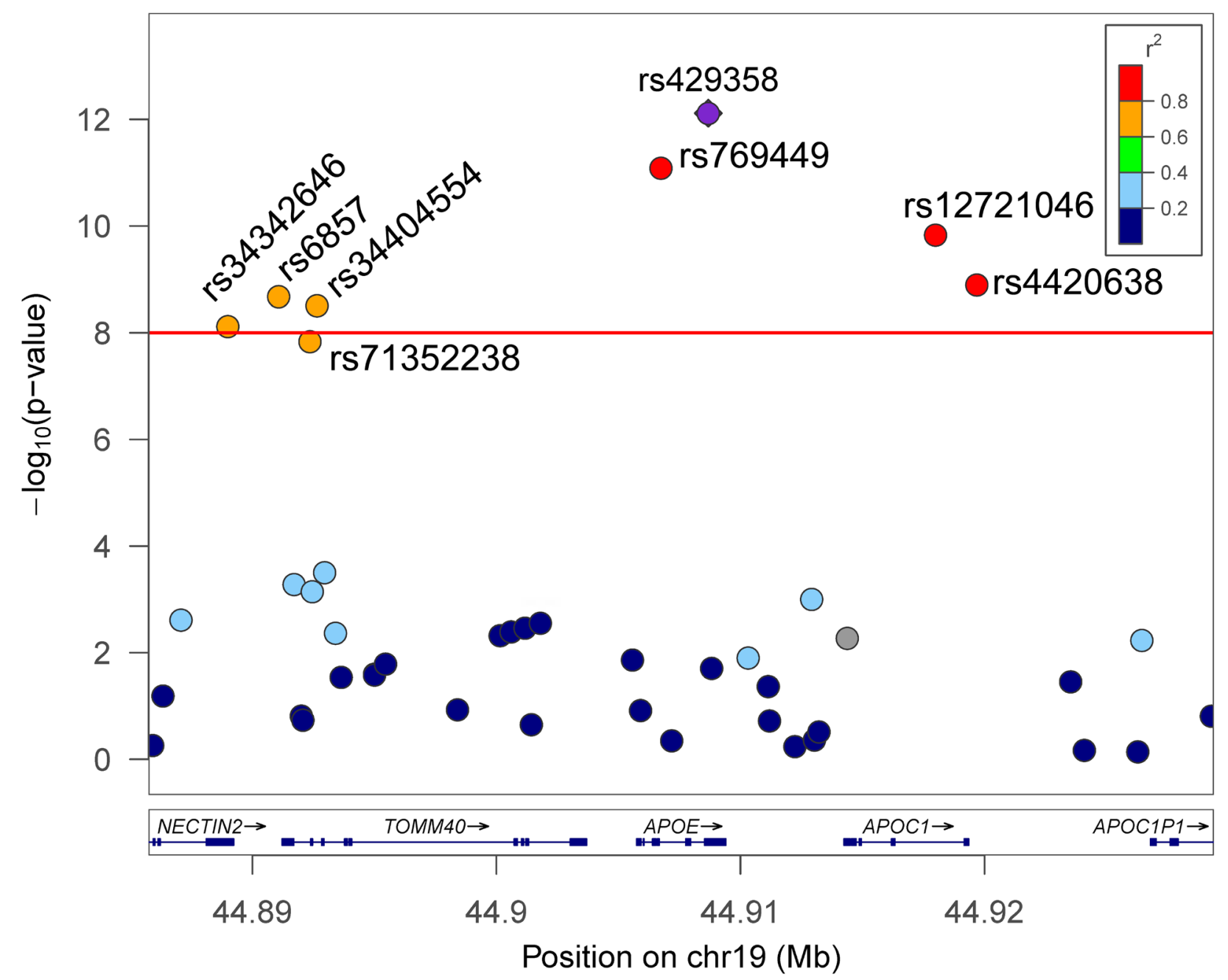

Figure 3 - Locuszoom plot illustrates the linkage disequilibrium and recombination rate between four genes in chromosome 19 in male participants. The genes include $A P O E, A P O C 1, P V R L 2$, and TOMM40. It showed the polymorphism rs429358 was the major variant for low high-density lipoprotein cholesterol in men.

gene is the only major variant for relating to lower HDL-C compared to the other variants located in genes $P V R L 2$, APOC1, and TOMM40.

Compared with those with genotype CC of rs 1364422 located in the KLF14 gene, cases with genotype TT had 1.30 $(95 \% \mathrm{CI}=1.20-1.42)$ times the risk for low-HDL-C in females $(-\log (p)=8.98$; Table 2$)$, but the same effect was not indicated in males $(p=0.166)$. Furthermore, those with genotype TT also have a higher prevalence of low-HDL-C than those with genotypes CT or CC in females $(34.52 \%, 31.27 \%, 28.79 \%$, respectively; $p$ for trend $\left.<1 \times 10^{-8}\right)$. The above result suggests that the rs1364422 $\mathrm{T}$ allele could be different from the $\mathrm{C}$ allele in physiologic function. For the male-specific genes related to low-HDL-C, we only demonstrated the OR and $95 \%$ CI of the top significant variant of each gene in Table 2. The polymorphism rs429358 located in the APOE gene acted as the major candidate variant for the male-specific variant through the LD exclusion by Locuszoom plot. The result showed that those with genotype CT of rs429358 had $1.24(95 \% \mathrm{CI}=1.16-1.32)$ times the risk of becoming lower HDL-C, which occurred only in males $(-\log (\mathrm{p})=9.22)$. The other polymorphisms located in genes APOC1, PVRL2, and TOMM40 also showed high associations with lower HDL-C; the $p$-values have fallen in the range $1 \times 10^{-6}$ and 1 $\mathrm{x} 10^{-8}$ in the male group (Table 2).

We estimated the mean differences of HDL-C among genotypes of the sex-specific polymorphisms related to lowHDL-C, such as rs1364422, rs429358, rs4420638, rs34342646 and rs34404554. Except for the polymorphism rs1364422, which did not reveal any significant difference of HDL-C related to the genotypes in males ( $p=0.298$; Table 3 ), the mean difference in females also remains high significant difference $(-\log (p)=4.76)$. Besides, the other variants showed highly significant differences of the HDL-C with different genotypes in both sexes (all $p$-values $<0.0001$ ).

The ORs of loci and the allele information which significantly related to low-HDL-C occurred in both genders are listed in Table 4. We only listed the top significant variant of each gene related to low-HDL-C. The results revealed that the variants with homozygous genotypes of polymorphisms rs261291 (ALDH1A2), rs2070895 (LIPC), rs17231506 (CETP), rs247616 (HERPUD1), and rs9958734 (LIPG) have strong protective effects against lowering HDL-C compared to those with wild type (all $-\log (\mathrm{p})>10)$. One exception is that a variant 
Table 2 - ORs and allele information of polymorphisms which were sex-specific related to low-HDL-C.

\begin{tabular}{|c|c|c|c|c|c|c|c|c|c|c|}
\hline \multirow[b]{2}{*}{ SNP } & \multirow[b]{2}{*}{ Chr. } & \multirow[b]{2}{*}{ Position } & \multirow[b]{2}{*}{ Gene } & \multirow[b]{2}{*}{ Alt. } & \multicolumn{3}{|c|}{ Males $(n=20763)$} & \multicolumn{3}{|c|}{ Females $(n=20763)$} \\
\hline & & & & & Case $(\%)$ & $\begin{array}{c}\mathrm{OR} \\
(95 \% \mathrm{CI}) \\
\end{array}$ & $\begin{array}{c}-\log \\
(p \text {-value })\end{array}$ & Case $(\%)$ & $\begin{array}{c}\text { OR } \\
(95 \% \mathrm{CI}) \\
\end{array}$ & $\begin{array}{c}-\log \\
(p-\text { value })\end{array}$ \\
\hline \multirow[t]{4}{*}{ rs1364422 } & 7 & 130761222 & KLF14 & $\mathrm{T}$ & & & & & & \\
\hline & & $\mathrm{TT}$ & & & $973(25.79)$ & $0.94(0.86-1.03)$ & 0.81 & $1282(34.52)$ & $1.30(1.20-1.42)$ & 8.98 \\
\hline & & $\mathrm{CT}$ & & & $2755(27.39)$ & $1.02(0.95-1.09)$ & 0.20 & $3153(31.27)$ & $1.13(1.05-1.20)$ & 3.27 \\
\hline & & $\mathrm{CC}$ & & & $1867(27.06)$ & 1.0 & & $1996(28.79)$ & 1.0 & \\
\hline \multirow[t]{4}{*}{ rs429358 } & 19 & 44908684 & $A P O E$ & $\mathrm{C}$ & & & & & & \\
\hline & & $\mathrm{CC}$ & & & $42(34.15)$ & $1.32(0.96-1.76)$ & 1.11 & $47(38.84)$ & $1.28(0.94-1.68)$ & 1.02 \\
\hline & & $\mathrm{CT}$ & & & $1032(32.14)$ & $1.24(1.16-1.32)$ & 9.22 & $1109(34.39)$ & $1.13(1.06-1.20)$ & 3.62 \\
\hline & & $\mathrm{TT}$ & & & $4453(25.95)$ & 1.0 & & $5103(30.45)$ & 1.0 & \\
\hline \multirow[t]{4}{*}{ rs4420638 } & 19 & 44919689 & $A P O C 1$ & G & & & & & & \\
\hline & & GG & & & $69(33.82)$ & $1.26(0.99-1.58)$ & 1.30 & $69(34.33)$ & $1.13(0.88-1.42)$ & 0.49 \\
\hline & & GA & & & $1159(30.86)$ & $1.18(1.11-1.26)$ & 6.42 & $1274(33.56)$ & $1.10(1.04-1.17)$ & 2.74 \\
\hline & & AA & & & $4374(26.04)$ & 1.0 & & $5102(30.44)$ & 1.0 & \\
\hline \multirow[t]{4}{*}{ rs34342646 } & 19 & 44884873 & PVRL2 & A & & & & & & \\
\hline & & AA & & & $49(36.03)$ & $1.38(1.03-1.80)$ & 1.59 & $47(36.15)$ & $1.18(0.87-1.56)$ & 0.60 \\
\hline & & GA & & & $964(31.27)$ & $1.20(1.11-1.28)$ & 6.32 & $1048(33.44)$ & $1.09(1.02-1.17)$ & 2.09 \\
\hline & & GG & & & $4589(26.16)$ & 1.0 & & $5348(30.58)$ & 1.0 & \\
\hline \multirow[t]{4}{*}{ rs34404554 } & 19 & 44891079 & TOMM40 & $\mathrm{G}$ & & & & & & \\
\hline & & GG & & & $50(35.71)$ & $1.37(1.02-1.78)$ & 1.54 & $47(35.07)$ & $1.15(0.85-1.51)$ & 0.46 \\
\hline & & $\mathrm{CG}$ & & & 965 (31.19) & $1.19(1.11-1.28)$ & 6.16 & $1054(33.47)$ & $1.09(1.02-1.17)$ & 2.14 \\
\hline & & $\mathrm{CC}$ & & & $4584(26.16)$ & 1.0 & & $5341(30.57)$ & 1.0 & \\
\hline
\end{tabular}

OR: odds ratio; 95\% CI: 95\% confident intervals; The ORs were estimated by logistic regression after adjustment of body mass index, total cholesterol and triglycerides. HDL-C: high-density lipoprotein cholesterol; Chr: chromosome; Alt: alternative allele.

Table 3 - Mean values of HDL-C among the polymorphisms which were sex-specific related to low-HDL-C.

\begin{tabular}{|c|c|c|c|c|c|c|c|}
\hline \multirow{2}{*}{ SNP } & \multirow{2}{*}{ Genotypes } & \multicolumn{3}{|c|}{ Males $(n=20763)$} & \multicolumn{3}{|c|}{ Females $(n=20763)$} \\
\hline & & No. & mean $\pm \mathrm{SD}(\mathrm{mg} / \mathrm{dl})$ & $-\log (\mathrm{p})$ post hoc & No. & mean $\pm \mathrm{SD}(\mathrm{mg} / \mathrm{dl})$ & $-\log (p)$ post hoc \\
\hline \multicolumn{8}{|c|}{ rs1364422 } \\
\hline & $\mathrm{TT}^{\mathrm{a}}$ & 3773 & $48.04 \pm 11.22$ & 0.526 & 3714 & $57.11 \pm 13.25$ & $\begin{array}{c}4.76 \\
a<c, b<c\end{array}$ \\
\hline & $\mathrm{CT}^{\mathrm{b}}$ & 10059 & $47.76 \pm 11.09$ & & 10082 & $57.94 \pm 13.26$ & \\
\hline & $\mathrm{CC}^{\mathrm{c}}$ & 6900 & $47.71 \pm 11.09$ & & 6933 & $58.37 \pm 12.97$ & \\
\hline \multicolumn{8}{|c|}{ rs429358 } \\
\hline & $\mathrm{CC}^{\mathrm{a}}$ & 123 & $46.43 \pm 10.98$ & $\begin{array}{c}10.89 \\
b<c\end{array}$ & 121 & $55.15 \pm 13.25$ & $\begin{array}{c}9.63 \\
b / c, a<c\end{array}$ \\
\hline & $\mathrm{CT}^{\mathrm{b}}$ & 3211 & $46.55 \pm 11.03$ & & 3225 & $56.60 \pm 13.06$ & \\
\hline & $\mathrm{TT}^{\mathrm{c}}$ & 17158 & $48.04 \pm 11.12$ & & 16761 & $58.19 \pm 13.20$ & \\
\hline \multicolumn{8}{|c|}{ rs4420638 } \\
\hline & $\mathrm{GG}^{\mathrm{a}}$ & 204 & $46.22 \pm 11.29$ & $\begin{array}{l}9.80 \\
b<c\end{array}$ & 201 & $56.39 \pm 12.51$ & $\begin{array}{l}7.38 \\
b<c\end{array}$ \\
\hline & $\mathrm{GA}^{\mathrm{b}}$ & 3756 & $46.76 \pm 10.87$ & & 3796 & $56.87 \pm 13.03$ & \\
\hline & $\mathrm{AA}^{\mathrm{c}}$ & 16795 & $48.04 \pm 11.15$ & & 16761 & $58.19 \pm 13.20$ & \\
\hline \multicolumn{8}{|c|}{ rs34342646 } \\
\hline & $\mathrm{AA}^{\mathrm{a}}$ & 136 & $45.76 \pm 11.17$ & $\begin{array}{l}7.89 \\
b<c\end{array}$ & 130 & $55.59 \pm 13.01$ & $\begin{array}{l}6.31 \\
b<c\end{array}$ \\
\hline & $\mathrm{GA}^{\mathrm{b}}$ & 3083 & $46.77 \pm 11.03$ & & 3134 & $56.86 \pm 12.94$ & \\
\hline & $\mathrm{GG}^{\mathrm{c}}$ & 17543 & $47.99 \pm 11.12$ & & 17491 & $58.14 \pm 13.20$ & \\
\hline \multicolumn{8}{|c|}{ rs34404554 } \\
\hline & $\mathrm{GG}^{\mathrm{a}}$ & 140 & $45.79 \pm 11.06$ & $\begin{array}{l}7.74 \\
b<c\end{array}$ & 134 & $55.87 \pm 13.04$ & $\begin{array}{l}6.36 \\
b<c\end{array}$ \\
\hline & $\mathrm{CG}^{\mathrm{b}}$ & 3094 & $46.78 \pm 11.04$ & & 3149 & $56.84 \pm 12.92$ & \\
\hline & $\mathrm{CC}^{\mathrm{c}}$ & 17521 & $47.99 \pm 11.12$ & & 17469 & $58.14 \pm 13.21$ & \\
\hline
\end{tabular}


Table 4 - The ORs and allele information of polymorphisms which were significantly related to low-HDL-C in both males and females.

\begin{tabular}{|c|c|c|c|c|c|c|c|c|c|c|}
\hline \multirow[b]{2}{*}{ Variants } & \multirow[b]{2}{*}{ Chr. } & \multirow[b]{2}{*}{ Position } & \multirow[b]{2}{*}{ Gene } & \multirow[b]{2}{*}{ Alt. } & \multicolumn{3}{|c|}{ Males $(n=20763)$} & \multicolumn{3}{|c|}{ Females $(\mathrm{n}=20763)$} \\
\hline & & & & & Case $(\%)$ & $\begin{array}{c}\text { OR } \\
(95 \% \mathrm{CI})\end{array}$ & $\begin{array}{c}-\log \\
(p \text {-value })\end{array}$ & Case $(\%)$ & $\begin{array}{c}\text { OR } \\
(95 \% \mathrm{CI})\end{array}$ & $\begin{array}{c}-\log \\
(p \text {-value })\end{array}$ \\
\hline \multirow[t]{4}{*}{ rs 17482753} & 8 & 199751350 & $L P L$ & $\mathrm{~T}$ & & & & & & \\
\hline & & $\mathrm{TT}$ & & & 35 (18.13) & $0.64(0.45-0.88)$ & 2.03 & $47(21.08)$ & $0.65(0.48-0.86)$ & 2.47 \\
\hline & & GT & & & $822(22.03)$ & $0.78(0.72-0.84)$ & 10.23 & $995(25.80)$ & $0.80(0.74-0.85)$ & 10.35 \\
\hline & & GG & & & $4740(28.20)$ & 1.0 & & $5396(32.39)$ & 1.0 & \\
\hline \multirow[t]{4}{*}{ Affx 4282911} & 11 & 116790676 & $A P O A 5$ & A & & & & & & \\
\hline & & $\mathrm{AA}$ & & & $71(66.98)$ & $2.65(2.07-3.32)$ & 15.38 & $64(66.67)$ & $2.28(1.76-2.89)$ & 10.24 \\
\hline & & $\mathrm{CA}$ & & & $952(37.06)$ & $1.46(1.36-1.57)$ & 25.96 & $1087(42.21)$ & $1.44(1.35-1.54)$ & 27.45 \\
\hline & & $\mathrm{CC}$ & & & $4575(25.32)$ & 1.0 & & $5290(29.26)$ & 1.0 & \\
\hline \multirow[t]{4}{*}{ rs7350481 } & 11 & 116715567 & $B U D 13$ & $\mathrm{C}$ & & & & & & \\
\hline & & $\mathrm{CC}$ & & & $457(38.12)$ & $1.55(1.41-1.71)$ & 17.78 & $496(40.82)$ & $1.42(1.29-1.56)$ & 12.59 \\
\hline & & $\mathrm{TC}$ & & & $2185(29.20)$ & $1.19(1.13-1.26)$ & 9.22 & $2481(33.20)$ & $1.16(1.10-1.22)$ & 7.40 \\
\hline & & $\mathrm{TT}$ & & & $2958(24.52)$ & 1.0 & & $3469(28.74)$ & 1.0 & \\
\hline \multirow[t]{4}{*}{ rs2160669 } & 11 & 116776891 & $Z P R 1$ & $\mathrm{~T}$ & & & & & & \\
\hline & & $\mathrm{TT}$ & & & $354(38.23)$ & $1.52(1.36-1.70)$ & 13.32 & $341(39.84)$ & $1.34(1.20-1.49)$ & 6.62 \\
\hline & & $\mathrm{CT}$ & & & $1952(29.20)$ & $1.16(1.10-1.23)$ & 6.98 & $2184(32.43)$ & $1.09(1.03-1.15)$ & 2.89 \\
\hline & & $\mathrm{CC}$ & & & $3285(25.08)$ & 1.0 & & 3905 (29.76) & 1.0 & \\
\hline \multirow[t]{4}{*}{ rs261291 } & 15 & 58387979 & $A L D H 1 A 2$ & $\mathrm{C}$ & & & & & & \\
\hline & & $\mathrm{CC}$ & & & $759(21.56)$ & $0.66(0.60-0.72)$ & 17.56 & $926(26.75)$ & $0.72(0.66-0.79)$ & 11.67 \\
\hline & & $\mathrm{TC}$ & & & $2731(27.10)$ & $0.89(0.83-0.95)$ & 3.32 & 3125 (30.77) & $0.88(0.83-0.94)$ & 3.82 \\
\hline & & $\mathrm{TT}$ & & & $2104(37.61)$ & 1.0 & & $2375(33.50)$ & 1.0 & \\
\hline \multirow[t]{4}{*}{ rs2070895 } & 15 & 58431740 & $L I P C$ & A & & & & & & \\
\hline & & AA & & & $700(23.33)$ & $0.71(0.64-0.78)$ & 11.51 & $831(26.76)$ & $0.72(0.66-0.79)$ & 11.34 \\
\hline & & GA & & & $2518(25.64)$ & $0.80(0.75-0.86)$ & 10.17 & 2937 (30.33) & $0.86(0.81-0.92)$ & 5.38 \\
\hline & & GG & & & $2374(30.05)$ & 1.0 & & $2663(33.58)$ & 1.0 & \\
\hline \multirow[t]{4}{*}{ rs17231506 } & 16 & 56960616 & CETP & $\mathrm{T}$ & & & & & & \\
\hline & & $\mathrm{TT}$ & & & $71(12.46)$ & $0.41(0.32-0.51)$ & 13.06 & $93(15.71)$ & $0.46(0.37-0.56)$ & 12.85 \\
\hline & & $\mathrm{CT}$ & & & $1128(19.80)$ & $0.65(0.61-0.70)$ & 37.04 & $1419(24.97)$ & $0.73(0.69-0.78)$ & 24.17 \\
\hline & & $\mathrm{CC}$ & & & $4391(30.40)$ & 1.0 & & $4923(34.06)$ & 1.0 & \\
\hline \multirow[t]{4}{*}{ rs247616 } & 16 & 56955678 & HERPUDI & $\mathrm{T}$ & & & & & & \\
\hline & & TT & & & $67(11.92)$ & $0.39(0.31-0.50)$ & 13.47 & $92(15.54)$ & $0.46(0.37-0.56)$ & 13.00 \\
\hline & & $\mathrm{CT}$ & & & $1129(19.92)$ & $0.66(0.62-0.70)$ & 35.58 & $1418(25.08)$ & $0.74(0.70-0.78)$ & 23.22 \\
\hline & & $\mathrm{CC}$ & & & $4402(30.31)$ & 1.0 & & $4930(34.00)$ & 1.0 & \\
\hline \multirow[t]{4}{*}{ rs9958734 } & 18 & 49592028 & $L I P G$ & $\mathrm{C}$ & & & & & & \\
\hline & & $\mathrm{CC}$ & & & $792(23.12)$ & $0.72(0.65-0.79)$ & 11.43 & $911(27.02)$ & $0.73(0.67-0.80)$ & 10.79 \\
\hline & & $\mathrm{TC}$ & & & $2634(26.44)$ & $0.86(0.80-0.92)$ & 5.18 & $3066(30.56)$ & $0.87(0.82-0.93)$ & 4.47 \\
\hline & & TT & & & $2163(29.55)$ & 1.0 & & $2451(33.53)$ & 1.05 & \\
\hline \multirow[t]{4}{*}{ rs2278426 } & 19 & 11239812 & ANGPTL8 & $\mathrm{T}$ & & & & & & \\
\hline & & $\mathrm{TT}$ & & & $438(32.74)$ & $1.29(1.17-1.43)$ & 6.27 & $557(39.70)$ & $1.37(1.25-1.50)$ & 11.11 \\
\hline & & $\mathrm{CT}$ & & & $2257(28.35)$ & $1.12(1.06-1.18)$ & 4.25 & $2580(32.36)$ & $1.12(1.06-1.17)$ & 4.48 \\
\hline & & $\mathrm{CC}$ & & & $2887(25.32)$ & 1.0 & & $3285(29.02)$ & 1.0 & \\
\hline \multirow[t]{4}{*}{ rs3760782 } & 19 & 11235874 & DOCK6 & $\mathrm{T}$ & & & & & & \\
\hline & & $\mathrm{TT}$ & & & $451(32.87)$ & $1.30(1.17-1.43)$ & 6.50 & $562(39.03)$ & $1.35(1.23-1.47)$ & 10.17 \\
\hline & & $\mathrm{CT}$ & & & $2254(28.28)$ & $1.11(1.05-1.18)$ & 3.95 & $2586(32.54)$ & $1.12(1.07-1.18)$ & 5.00 \\
\hline & & $\mathrm{CC}$ & & & $2889(25.37)$ & 1.0 & & 3287 (28.97) & 1.0 & \\
\hline
\end{tabular}

OR: odds ratio; $95 \%$ CI: 95\% confidence intervals; The ORs were estimated by logistic regression after adjustment of body mass index, total cholesterol and triglycerides. HDL-C: high-density lipoprotein cholesterol; Chr: chromosome; Alt: alternative allele. OR equal to 1.0 indicates that acts as referent group. 
with heterozygous genotype of polymorphism rs17482753 $(L P L)$ also showed its protective effect in both genders $(-\log (\mathrm{p})>=10)$. Moreover, the loci with homozygous genotypes of polymorphisms Affx4282911 (APOA5), rs7350481 (BUD13), rs2160669 (ZPR1), rs2278426 (ANGPTL8), and rs3760782 (DOCK6) showed a deleterious effect on HDL-C (all $-\log (\mathrm{p})>6)$; especially, all the polymorphisms showed a higher-dose response of lowering HDL-C levels with the number of allelic variants ( $p$-values test for trend, all $-\log (p)>10$ in both genders).

Moreover, we further estimated the relationships between low-HDL-C and current uses of tobacco smoking and alcohol consumption. The results showed that both effects on lowHDL-C were dominant in males, that tobacco smoking exhibited a higher risk of causing low-HDL-C (OR=1.87, $95 \% \mathrm{CI}=1.74-2.01,-\log (\mathrm{p})=65.61)$, and alcohol consumption showed a protective effect $(\mathrm{OR}=0.70,95 \% \mathrm{CI}=0.64-0.77$, $-\log (p)=12.19$; Table 5). To avoid the confounding effects of tobacco smoking and alcohol consumption on low-HDL-C, we further estimated the associations between polymorphisms of rs1364422 and rs429358 by adjusting the uses of these two lifestyle habits. The results showed polymorphism rs1364422 has significant effect on low-HDL-C in females, and polymorphism rs429358 showed significant effect in males.

\section{Discussion}

The development of low HDL-C could be characterized by genetic, environmental factors, gene-lifestyle interactions (Williams, 2021) as well as gender heterogeneity. We performed a GWAS study to reveal the genetic variants associated with low-HDL-C and found twelve genes related to HDL-C in both genders. Our results also demonstrated that the gene KLF14 was dominantly related to HDL-C in females, and that the genes APOC1, APOE, PVRL2, and TOMM40 were significantly associated with low-HDL-C only in males. With reference to the literature, we summarize the gene functions of those with the sex-specific effects in a table (Table S3), and found that the five genes, namely, KLF14, APOE, TOMM40, APOC1, PVRL2 are found to have associated impact on HDL-C, LDL-C and total cholesterol levels. The KLF family is identified as a class of evolutionarily conserved transcription factors that have a zinc finger domain. It was commonly agreed that these genes regulate many types of cellular processes such as apoptosis, metabolism, proliferation, and differentiation (Lomberk and Urrutia, 2005). Some GWAS results also disclosed that genetic variants surrounding the KLF14 gene are closely linked to type 2 diabetes, HDL-C levels, metabolic syndrome, HbA1C, and atherosclerosis (Teslovich et al., 2010; Small et al., 2011; Chen et al., 2012; Elouej et al., 2016; Shahvazian et al., 2021). Recently discovered as belonging to the KLF family, KLF14 was found to regulate cholesterol efflux through inhibiting inflammatory response in macrophages and the expression of $A B C A 1$ (Wang et al., 2021).

In addition, gender discrepancy is an important issue in how KLF14 functions. Scholars have examined KLF14 physiologically with a whole-body knockout mouse model (Argmann et al., 2017). Exploring this transcription factor's metabolic role on the function of HDL-C and insulin resistance in female mice was positive, but the results showed that the metabolic phenotypes of male mice were not affected by KLF14
(Argmann et al., 2017). Furthermore, applying a sex-stratified meta-analysis of GWAS data, Small et al. discovered that females had larger effect sizes and higher KLF14 expression than males on the metabolic components, such as HDL-C, triglycerides, BMI, fasting glucose, and fasting insulin (Small et al., 2018). All the aforementioned findings as well as our result suggested that KLF14 is a female-specific gene for low-HDL-C.

To investigate whether there is a different transcription factor binding site between the two alleles of rs1364422 (allele $\mathrm{T}$ and $\mathrm{C} ; \mathrm{KLF} 14$ gene), PROMO3.0 was applied to find the transcription factor binding sites in DNA sequences (Messeguer et al., 2002). Using the strictest criteria (0\%, maximum matrix dissimilarity rate), we found a Yin-Yang member 1 (YY1) binding site in $\mathrm{T}$ allele, but not in $\mathrm{C}$ allele. As known, "Yin" means negative or repressing; "Yang" means positive or activating. The YY1 is an important transcription factor, included in the GLI-Kruppel class zinc finger proteins. Zinc finger protein can activate and repress a various number of promoters. Weintraub et al. (2017) reported that through promoting DNA interactions and forming dimers, YY1 could promote enhancer-promoter chromatin loops. Hence, its dysregulation would disrupt enhancer-promoter loops and gene expression (Gabriele et al., 2017). From the above, higher frequency of low-HDL-C risk and lower HDL-C levels associated with the $\mathrm{T}$ allele of rs 1364422 could be realized by creating the $\mathrm{YY} 1$ binding site of $\mathrm{T}$ allele, but not $\mathrm{C}$ allele.

All four genes related to low-HDL-C in males are located closely in chromosome 19 . The genes located in a close region show a higher degree of LD between them, including genes APOE, APOC1, PVRL2, and TOMM40. Especially, for the APOE gene, Braeckman et al. (1996) revealed that in comparison with the most commonly detected $A P O E \varepsilon 3 / \varepsilon 3$ phenotype, the $\varepsilon 2$ allele was linked to a higher HDL-C levels independently of lifestyle factors, $A P O E$ levels, and age. Frikke-Schmidt et al. (2000) found the variations in $A P O E$ genotype predicted stepwise decreases with the presence of $\varepsilon 4$ in HDL-C for women, but not for men. The data explained two things: firstly, in addition to the well-known increasing effect on non-HDL cholesterol, through a decreasing effect on HDL-C, the $\varepsilon 4$ allele could further predispose to coronary heart disease; secondly, through both an increasing effect on HDL-C and a decreasing effect on non-HDL-C, the $\varepsilon 2$ allele could exert a protective influence (Braeckman et al., 1996).

For some of the genes identified as related to low-HDL-C in our study, their relationships to metabolic syndrome, HDL-C, or lipid dysfunction have been previously explored in the literature. For instance, ZPRI (Galcheva-Gargova et al., 1998; Corton et al., 2000) and BUD13 (Brooks et al., 2009) were well-documented for lipid level, HERPUD1 was found related to HDL-C in the Korean population (Oh et al., 2020), and the APOA5 and CETP also showed evidence of contributing to triglycerides, metabolic syndrome, and HDL-C (Talmud et al., 2009; Lin et al., 2016). The rate-limiting step of HDL-C biogenesis was mediated by ABCA1 by transporting cellular excess free phospholipids and cholesterol to an apolipoprotein acceptor (Brunham et al., 2007; Babashamsi et al., 2019). Some studies also provided a role of $A B C A 1$ between the decreased HDL-C and the increased triglycerides levels (Chung et al., 2010; Liu et al., 2017). Also, recent research illustrated ABCA1's role in additional metabolic 
Table 5 - ORs of relating to low-HDL-C for polymorphisms rs1364422 and rs429358 after adjusting tobacco smoking and alcohol consumption.

\begin{tabular}{|c|c|c|c|c|}
\hline \multirow[b]{2}{*}{ SNP } & \multicolumn{2}{|c|}{ Males $(n=20763)$} & \multicolumn{2}{|c|}{ Females $(\mathrm{n}=20763)$} \\
\hline & $\begin{array}{c}\mathrm{aOR} \\
(95 \% \mathrm{CI})\end{array}$ & $-\log (p$-value $)$ & $\begin{array}{c}\mathrm{aOR} \\
(95 \% \mathrm{CI})\end{array}$ & $-\log (p$-value $)$ \\
\hline \multicolumn{5}{|c|}{ Tobacco smoking } \\
\hline Yes & $1.87(1.74-2.01)$ & 65.61 & $1.43(1.21-1.70)$ & 4.40 \\
\hline No & 1.0 & & 1.0 & \\
\hline \multicolumn{5}{|c|}{ Alcohol consumption } \\
\hline Yes & $0.70(0.64-0.77)$ & 12.19 & $0.51(0.39-0.67)$ & 5.98 \\
\hline No & 1.0 & & 1.0 & \\
\hline \multicolumn{5}{|c|}{ rs1364422 } \\
\hline TT & $0.94(0.86-1.03)$ & 0.74 & $1.31(1.21-1.43)$ & 9.35 \\
\hline CT & $1.02(0.95-1.10)$ & 0.28 & $1.13(1.05-1.21)$ & 3.33 \\
\hline $\mathrm{CC}$ & 1.0 & & 1.0 & \\
\hline \multicolumn{5}{|c|}{ rs 429358} \\
\hline GG & $1.50(1.03-2.19)$ & 1.46 & $1.45(1.01-2.10)$ & 1.33 \\
\hline GA & $1.36(1.26-1.48)$ & 12.93 & $1.20(1.11-1.30)$ & 5.07 \\
\hline AA & 1.0 & & 1.0 & \\
\hline
\end{tabular}

aOR $(95 \% \mathrm{CI})$ : The odds ratios and $95 \%$ confidence intervals of relating to low-HDL-C were estimated for tobacco smoking and alcohol consumption after adjusting age; and estimated for rs 1364422 and rs429358 after adjusting age, smoking and alcohol consumption.

characteristics, revealing its relationship to decreased insulin secretion, sensitivity, and body weight, but to increased blood glucose levels (Brunham et al., 2007; de Haan et al., 2014; Sanchez-Aguilera et al., 2018).

Three genes in the lipase family -- $L P L, L I P C$ and $L I P G$-- were discovered to be related to low-HDL-C in our study. $L P L$ is significant in the hydrolysis of core triglycerides of circulating very low-density lipids and chylomicrons (Goldberg, 1996), and its methylation might be involved in triglyceride metabolism and affected by the degree of metabolic disturbances (Castellano-Castillo et al., 2018). Hepatic lipase is synthesized and secreted mainly from the liver (encoded by $L I P C)$; it is a glycoprotein in the triacylglycerol lipase family and participates in the hydrolysis of triglycerides and phospholipids (Annema and Tietge, 2011; Kobayashi et al., 2015). Liao et al. (2021) disclosed that HDL-C notably relates to variations in $L I P C$ through a genome-wide association analysis. Their study also explored the suppressive role of LIPC for triglycerides and found that HDL-C levels might be reduced by a functional haplotype of LIPC (Liao et al., 2021). Gene $L I P G$ (lipase $\mathrm{G}$ ) encodes the protein of endothelial lipase, functional on the main substrate, phospholipids in HDL-C, and hydrolysis of phospholipids. West et al. (1996) found that the LIPG genetic variant was significantly related to the mean plasma levels of HDL-C. Furthermore, a strong link of the variant and the ratio of HDL-C to LDL-C was apparent in different populations (Ma et al., 2003; Yang et al., 2019). Edmondson et al. (2009) established that increased HDL-C levels could be caused by loss-of-function mutations in $L I P G$. An animal study showed that overexpress of endothelial lipase had decreased HDL-C and lacking endothelial lipase had elevated levels of HDL-C (Cilingiroglu and Ballantyne, 2004).

In conclusion, extending beyond existing studies, we exclusively found that polymorphisms within ANGPTL8, $D O C K 6$, and $A L D H 1 A 2$ were linked to lower HDL-C levels for both genders. Moreover, we demonstrated the low-HDL-C is a sex-specific phenotype, proving that the genes $A P O E$ and $K L F 14$ are specific for men and women, respectively.

\section{Acknowledgement}

We thank the Ministry of Science and Technology of Taiwan for supporting this project (109-2320-B-039 -052)

\section{Conflict of Interest}

There is no conflict of interest that could be perceived as prejudicial to the impartiality of the reported research.

\section{Authors Contributions}

YHL, YSC and SJC wrote the draft manuscript; YHL, YSC, CCH, RTW and SJC analyzed the data; JGC, CJC and SJC conducted and supervised the study, conceived the study, provided the data source. All authors read and approved the final version.

\section{References}

Annema W and Tietge UJ (2011) Role of hepatic lipase and endothelial lipase in high-density lipoprotein-mediated reverse cholesterol transport. Curr Atheroscler Rep 13:257-265.

Argmann CA, Violante S, Dodatko T, Amaro MP, Hagen J, Gillespie VL, Buettner C, Schadt EE and Houten SM (2017) Germline deletion of Krüppel-like factor 14 does not increase risk of diet induced metabolic syndrome in male C57BL/6 mice. Biochim Biophys Acta Mol Basis Dis 1863:3277-3285.

Babashamsi MM, Koukhaloo SZ, Halalkhor S, Salimi A and Babashamsi M (2019) ABCA1 and metabolic syndrome; a review of the ABCA1 role in HDL-VLDL production, insulinglucose homeostasis, inflammation and obesity. Diabetes Metab Syndr 13:1529-1534.

Braeckman L, De Bacquer D, Rosseneu M and De Backer G (1996) Apolipoprotein E polymorphism in middle-aged Belgian men: Phenotype distribution and relation to serum lipids and lipoproteins. Atherosclerosis 120:67-73. 
Brooks MA, Dziembowski A, Quevillon-Cheruel S, Henriot V, Faux C, van Tilbeurgh H and Seraphin B (2009) Structure of the yeast Pml1 splicing factor and its integration into the RES complex. Nucleic Acids Res 37:129-143.

Brunham LR, Kruit JK, Pape TD, Timmins JM, Reuwer AQ, Vasanji Z, Marsh BJ, Rodrigues B, Johnson JD, Parks JS et al. (2007) Beta-cell ABCA1 influences insulin secretion, glucose homeostasis and response to thiazolidinedione treatment. Nat Med 13:340-347.

Castellano-Castillo D, Moreno-Indias I, Fernández-García JC, AlcaideTorres J, Moreno-Santos I, Ocaña L, Gluckman E, Tinahones F, Queipo-Ortuño MI and Cardona F (2018) Adipose tissue LPL methylation is associated with triglyceride concentrations in the metabolic syndrome. Clin Chem 64:210-218.

Chen X, Li S, Yang Y, Yang X, Liu Y, Liu Y, Hu W, Jin L and Wang $X$ (2012) Genome-wide association study validation identifies novel loci for atherosclerotic cardiovascular disease. J Thromb Haemost 10:1508-1514.

Chung S, Gebre AK, Seo J, Shelness GS and Parks JS (2010) A novel role for ABCA1-generated large pre-beta migrating nascent HDL in the regulation of hepatic VLDL triglyceride secretion. J Lipid Res 51:729-742.

Cilingiroglu M and Ballantyne C (2004) Endothelial lipase and cholesterol metabolism. Curr Atheroscler Rep 6:126-130.

Corton JC, Anderson SP and Stauber A (2000) Central role of peroxisome proliferator-activated receptors in the actions of peroxisome proliferators. Annu Rev Pharmacol Toxicol 40:491-518.

de Graaf J and Stalenhoef AF (1998) Defects of lipoprotein metabolism in familial combined hyperlipidaemia. Curr Opin Lipidol 9:189-196.

de Haan W, Bhattacharjee A, Ruddle P, Kang MH and Hayden MR (2014) ABCA1 in adipocytes regulates adipose tissue lipid content, glucose tolerance, and insulin sensitivity. J Lipid Res 55:516-523.

Edmondson AC, Brown RJ, Kathiresan S, Cupples LA, Demissie S, Manning AK, Jensen MK, Rimm EB, Wang J, Rodrigues A et al. (2009) Loss-of-function variants in endothelial lipase are a cause of elevated HDL cholesterol in humans. J Clin Invest 119:1042-1050.

Elouej S, Rejeb I, Attaoua R, Nagara M, Sallem OK, Kamoun I, Chargui M, Jamoussi H, Turki Z, Abid A et al. (2016) Gender-specific associations of genetic variants with metabolic syndrome components in the Tunisian population. Endocr Res 41:300-309.

Emerging Risk Factors Collaboration; Di Angelantonio E, Sarwar N, Perry P, Kaptoge S, Ray KK, Thompson A, Wood AM, Lewington S, Sattar N et al. (2009) Major lipids, apolipoproteins, and risk of vascular disease. JAMA 302:1993-2000.

Frikke-Schmidt R, Nordestgaard BG, Agerholm-Larsen B, Schnohr P and Tybjaerg-Hansen A (2000) Context-dependent and invariant associations between lipids, lipoproteins, and apolipoproteins and apolipoprotein E genotype. J Lipid Res 41:1812-1822.

Gabriele M, Vulto-van Silfhout AT, Germain $P$-L, Vitriolo A, Kumar R, Douglas E, Haan E, Kosaki K, Takenouchi T, Rauch A et al. (2017) YY1 haploinsufficiency causes an intellectual disability syndrome featuring transcriptional and chromatin dysfunction. Am J Hum Genet 100:907-925.

Galcheva-Gargova Z, Gangwani L, Konstantinov KN, Mikrut M, Theroux SJ, Enoch T and Davis RJ (1998) The cytoplasmic zinc finger protein ZPR1 accumulates in the nucleolus of proliferating cells. Mol Biol Cell 9:2963-2971.

Genest JJ Jr., Martin-Munley SS, McNamara JR, Ordovas JM, Jenner J, Myers RH, Silberman SR, Wilson PW, Salem DN and Schaefer EJ (1992) Familial lipoprotein disorders in patients with premature coronary artery disease. Circulation 85:2025-2033.
Goldberg IJ (1996) Lipoprotein lipase and lipolysis: Central roles in lipoprotein metabolism and atherogenesis. J Lipid Res 37:693-707.

Goldstein JL, Schrott HG, Hazzard WR, Bierman EL and Motulsky AG (1973) Hyperlipidemia in coronary heart disease. II. Genetic analysis of lipid levels in 176 families and delineation of a new inherited disorder, combined hyperlipidemia. J Clin Invest 52:1544-1568.

Hopkins PN, Heiss G, Ellison RC, Province MA, Pankow JS, Eckfeldt JH and Hunt SC (2003) Coronary artery disease risk in familial combined hyperlipidemia and familial hypertriglyceridemia: A case-control comparison from the National Heart, Lung, and Blood Institute Family Heart Study. Circulation 108:519-523.

Kobayashi J, Miyashita K, Nakajima K and Mabuchi H (2015) Hepatic lipase: A comprehensive view of its role on plasma lipid and lipoprotein metabolism. J Atheroscler Thromb 22:1001-1011.

Laks R, Araujo LM, Almada Filho C de M and Cendoroglo MS (2011) The importance of HDL-C and CRP in cardiovascular risk evaluation in longevous elderly individuals. Einstein (São Paulo) 9:397-403.

Lazo-Porras M, Bernabe-Ortiz A, Málaga G, Gilman RH, AcuñaVillaorduña A, Cardenas-Montero D, Smeeth L and Miranda JJ (2016) Low HDL cholesterol as a cardiovascular risk factor in rural, urban, and rural-urban migrants: PERU MIGRANT cohort study. Atherosclerosis 246:36-43.

Liao Y-H, Er L-K, Wu S, Ko Y-L and Teng M-S (2021) Functional haplotype of LIPC induces triglyceride-mediated suppression of HDL-C levels according to genome-wide association studies. Genes (Basel) 12:148.

Lin E, Kuo $P$-H, Liu Y-L, Yang AC, Kao C-F and Tsai S-J (2016) Association and interaction of APOA5, BUD13, CETP, LIPA and health-related behavior with metabolic syndrome in a Taiwanese population. Sci Rep 6:36830.

Liu M, Chung S, Shelness GS and Parks JS (2017) Hepatic ABCA1 deficiency is associated with delayed apolipoprotein B secretory trafficking and augmented VLDL triglyceride secretion. Biochim Biophys Acta Mol Cell Biol Lipids 1862:1035-1043.

Lomberk G and Urrutia R (2005) The family feud: Turning off Sp1 by Sp1-like KLF proteins. Biochem J 392:1-11.

Ma K, Cilingiroglu M, Otvos JD, Ballantyne CM, Marian AJ and Chan L (2003) Endothelial lipase is a major genetic determinant for high-density lipoprotein concentration, structure, and metabolism. Proc Natl Acad Sci U S A 100:2748-2753.

Messeguer X, Escudero R, Farré D, Núñez O, Martínez J and Albà MM (2002) PROMO: Detection of known transcription regulatory elements using species-tailored searches. Bioinformatics 18:333-334.

Oh S-W, Lee J-E, Shin E, Kwon H, Choe EK, Choi S-Y, Rhee H and Choi SH (2020) Genome-wide association study of metabolic syndrome in Korean populations. PLoS One 15:e0227357.

Pruim RJ, Welch RP, Sanna S, Teslovich TM, Chines PS, Gliedt TP, Boehnke M, Abecasis GR and Willer CJ (2010) LocusZoom: Regional visualization of genome-wide association scan results. Bioinformatics 26:2336-2337.

Sánchez-Aguilera P, Diaz-Vegas A, Campos C, Quinteros-Waltemath O, Cerda-Kohler H, Barrientos G, Contreras-Ferrat A and Llanos P (2018) Role of ABCA1 on membrane cholesterol content, insulin-dependent Akt phosphorylation and glucose uptake in adult skeletal muscle fibers from mice. Biochim Biophys Acta Mol Cell Biol Lipids 1863:1469-1477.

Shahvazian E, Mahmoudi MB, Yazd EF, Gharibi S, Moghimi B, HosseinNia P and Mirzaei M (2021) The KLF14 variant is associated with type 2 diabetes and $\mathrm{HbA}(1 \mathrm{C})$ level. Biochem Genet 59:574-588. 
Small KS, Hedman AK, Grundberg E, Nica AC, Thorleifsson G, Kong A, Thorsteindottir U, Shin S-Y, Richards HB, GIANT Consortium et al. (2011) Identification of an imprinted master trans regulator at the KLF14 locus related to multiple metabolic phenotypes. Nat Genet 43:561-564.

Small KS, Todorčević M, Civelek M, Moustafa JSE-S, Wang X, Simon MM, Fernandez-Tajes J, Mahajan A, Horikoshi M, Hugill A et al. (2018) Regulatory variants at KLF14 influence type 2 diabetes risk via a female-specific effect on adipocyte size and body composition. Nat Genet 50:572-580.

Soro A, Jauhiainen M, Ehnholm C and Taskinen M-R (2003) Determinants of low HDL levels in familial combined hyperlipidemia. J Lipid Res 44:1536-1544.

Souren NY, Paulussen ADC, Loos RJF, Gielen M, Beunen G, Fagard R, Derom C, Vlietinck R and Zeegers MP (2007) Anthropometry, carbohydrate and lipid metabolism in the east flanders prospective twin survey: Heritabilities. Diabetologia 50:2107-2116.

Talmud PJ, Drenos F, Shah S, Shah T, Palmen J, Verzilli C, Gaunt TR, Pallas J, Lovering R, Li K et al. (2009) Gene-centric association signals for lipids and apolipoproteins identified via the HumanCVD BeadChip. Am J Hum Genet 85:628-642.

Teslovich TM, Musunuru K, Smith AV, Edmondson AC, Stylianou IM, Koseki M, Pirruccello JP, Ripatti S, Chasman DI, Willer CJ et al. (2010) Biological, clinical and population relevance of 95 loci for blood lipids. Nature 466:707-713.

Turner SD (2014) qqman: An R package for visualizing GWAS results using Q-Q and manhattan plots. bioRxiv. DOI: 10.1101/005165

von Eckardstein A, Schulte H and Assmann G (2000) Risk for diabetes mellitus in middle-aged Caucasian male participants of the PROCAM study: Implications for the definition of impaired fasting glucose by the American Diabetes Association. Prospective Cardiovascular Munster. J Clin Endocrinol Metab 85:3101-3108.

Wang H, Guo Y, Lu H, Luo Y, Hu W, Liang W, Garcia-Barrio MT, Chang L, Schwendeman A, Zhang J et al. (2021) Krüppel-like factor 14 deletion in myeloid cells accelerates atherosclerotic lesion development. Cardiovasc Res:cvab027.

Weintraub AS, Li CH, Zamudio AV, Sigova AA, Hannett NM, Day DS, Abraham BJ, Cohen MA, Nabet B, Buckley DL et al. (2017) YY1 is a structural regulator of enhancer-promoter loops. Cell 171:1573-1588.e1528.
Weiss LA, Pan L, Abney M and Ober C (2006) The sex-specific genetic architecture of quantitative traits in humans. Nat Genet 38:218-222.

Weissglas-Volkov D and Pajukanta P (2010) Genetic causes of high and low serum HDL-cholesterol. J Lipid Res 51:2032-2057.

West MS, Herd JA, Ballantyne CM, Pownall HJ, Simpson S, Gould L and Gotto Jr AM (1996) The Lipoprotein and Coronary Atherosclerosis Study (LCAS): Design, methods, and baseline data of a trial of fluvastatin in patients without severe hypercholesterolemia. Control Clin Trials 17:550-583.

Willer CJ, Schmidt EM, Sengupta S, Peloso GM, Gustafsson S, Kanoni S, Ganna A, Chen J, Buchkovich ML, Mora S et al. (2013) Discovery and refinement of loci associated with lipid levels. Nat Genet 45:1274-1283.

Williams PT (2021) Quantile-dependent expressivity and genelifestyle interactions involving high-density lipoprotein cholesterol. Lifestyle Genom 14:1-19.

Wu Y, Waite LL, Jackson AU, Sheu WH, Buyske S, Absher D, Arnett DK, Boerwinkle E, Bonnycastle LL, Carty CL et al. (2013) Trans-ethnic fine-mapping of lipid loci identifies populationspecific signals and allelic heterogeneity that increases the trait variance explained. PLoS Genet 9:e1003379.

Yang S, Yin R-X, Miao L, Zhou Y-G, Wu J and Zhang Q-H (2019) LIPG SNPs, their haplotypes and gene-environment interactions on serum lipid levels. Lipids Health Dis 18:10.

\section{Supplementary material}

Table S1 - Information of genetic variants relating to lowHDL-C in males.

Table S2 - Information of genetic variants relating to lowHDL-C in females.

Table S3 - Gene functions which are sex-specifically associated significantly with HDL-C reviewed from the literature.

Associated Editor: Maria Luiza Petzl-Erler

License information: This is an open-access article distributed under the terms of the Creative Commons Attribution License (type CC-BY), which permits unrestricted use, istribution and reproduction in any medium, provided the original article is properly cited. 